\title{
Propagação vegetativa de romã com material vegetal de diferentes origens sob tipos de substratos
}

\section{Vegetative propagation of pomegranate with vegetal material of different origins under types of substrates}

\author{
Rômulo Magno Oliveira de Freitas ${ }^{1}$, Maria de Fatima Barbosa Coelho ${ }^{* 2}$, Narjara Walessa Nogueira ${ }^{3}$, Caio César Pereira \\ Leal $^{4}$, Andreya Kalyana de Oliveira ${ }^{3}$
}

Resumo: Objetivou-se com o presente trabalho verificar a influência de diferentes procedências do material vegetal e substratos na propagação vegetativa de romã (Punica granatum L.). Foi usado o delineamento estatístico inteiramente casualizado em esquema fatorial 2x3, sendo duas origens do material vegetal (Barreiras, CE e Mossoró, RN) e três substratos (Tropstrato $^{\circledR}$, Fibra de coco e Solo), constituindo 6 tratamentos em quatro repetições de cinco estacas. As estacas foram preparadas com o auxilio de uma tesoura de poda, coletadas na posição mediana do ramo, padronizadas para o diâmetro de 2 a $4 \mathrm{~mm}$. Aos 45 dias foram avaliados o número de brotos por estaca, comprimento do maior broto, número de folhas por estacas, comprimento da maior raiz, percentagem de estacas enraizadas, número de raízes por estaca, massa seca da brotação e massa seca do sistema radicular. A propagação por estaquia de romã é influenciada pela origem do material vegetal e o melhor material é de Barreiras, CE. Recomenda-se o substrato Tropstrato ${ }^{\circledR}$ para a produção de mudas de romã por estaquia.

Palavras-chave: Punica granatum, substratos comerciais, planta medicinal

\begin{abstract}
The objective of this study to investigate the influence of different sources of plant material and substrates in the vegetative propagation of pomegranate (Punica granatum L.). The statistical design was completely randomized in a $2 \times 3$ factorial, with two origins of the plant material collected (Barreiras, CE and Mossoró, RN) and three substrates (Tropstrato ${ }^{\circledR}$, Coconut fiber and soil), constituting six treatments and four replications. Each replication consisted of five cuttings. Cuttings were prepared with the aid of a pruning shears collected in the median position of the branch for the standardized diameter of 2 to $4 \mathrm{~mm}$. At 45 days, we assessed the number of shoots per cutting, length of the longest shoot, number of leaves per cutting, length of roots, rooting percentage, number of roots per cutting, dry weight and dry weight of sprouting root system. The propagation by cutting of pomegranate is influenced by the origin of the vegetal material and the best material is of Barreiras, CE. The Tropstrato ${ }^{\circledR}$ substrates are recommended for the production of pomegranate seedlings by cuttings.
\end{abstract}

Key words: Punica granatum, commercial substrates, medicinal plant

\footnotetext{
*Autor para correspondência

Recebido para publicação em 01/03/2016; aprovado em 05/02/2017

${ }^{1}$ Doutor, Instituto Federal Baiano, Valença-BA, CEP 45400-000 E-mail:romulomagno_23@hotmail.com

${ }^{2}$ Profa. Titular, Doutora, Universidade Federal de Mato Grosso, Cuiabá-MT, CEP 78060-900, E-mail: coelhomfstrela@gmail.com

${ }^{3}$ Doutora em Fitotecnia, Universidade Federal Rural do Semiárido, Mossoró-RN, CEP 57625-900 E-mail: narjarawalessa@ yahoo.com.br, oliver_andreya@yahoo.com.br

${ }^{4}$ Doutorando, Programa de Pós Graduação em Fitotecnia da UFERSA, Mossoró-RN, CEP 57625-900E-mail: caioleal3@ @otmail.com
} 


\section{INTRODUÇÃO}

A romã (Punica granatum L.) tem sido utilizada como planta frutífera, ornamental (parques e jardins) e reúne propriedades medicinais (CORREA, 1978). É uma planta perene nas regiões subtropicais e nas regiões temperadas, que forma arbusto que podem alcançar de 2 a 6 metros de altura, denso e ramoso com ramificações em formato de espinhas inclinadas e coloração verde brilhante, folhas ovais lanceoladas e flores solitárias, com corola vermelhoalaranjadas, sendo seguidas por frutos adocicados do tipo baga (LORENZI; MATOS, 2008).

As sementes de romã encontram-se recobertas pela sarcotesta, um material gelatinoso que pode vir a comprometer a germinação, tornando-a lenta e desuniforme (MARIN et al., 1987), sendo assim, faz-se de grande importância estudos sobre a propagação vegetativa desta espécie como uma alternativa para a uniformização de seu cultivo.

A propagação vegetativa por estaquia mostrou-se eficiente na multiplicação de diversas espécies medicinais, tais como crajiru (Arrabidaea chica) (FERREIRA; GONÇALVES, 2007); bamburral (Hyptis suaveolens) (MAIA et al., 2008); hortelã-japonesa (Mentha arvensis L.) (CHAGAS et al., 2008); liamba (Vitex agnus castus L.) (COELHO et al., 2011) e bamburral (Hyptis suaveolens) (SILVA et al., 2011); Cuphea calophylla (LUSA; BIASE, 2011) e Aloysia gratíssima (SANTOS et al., 2009).

A capacidade de uma estaca emitir raízes é função de fatores endógenos e das condições ambientais proporcionadas ao enraizamento, sendo o substrato um dos fatores de maior influência na propagação por estaquia, especialmente naquelas espécies com maior dificuldade de formação de raízes. O substrato não apenas afeta o percentual de estacas enraizadas, como também a qualidade do sistema radicular da muda. Destina-se a sustentar as estacas durante o enraizamento, mantendo sua base num ambiente úmido, escuro e suficientemente aerado (FACHINELLO et al., 2005).

Vários trabalhos evidenciam a influência de substratos na propagação vegetativa por estacas, a exemplo de Costa et al. (2007) em atroveran (Ocimum selloi); Carvalho et al. (2007) em carqueja (Baccharis trimera); Lima et al. (2008) em espinheira-santa (Maytenus ilicifolia); Oliveira et al. (2011) em alecrim de tabuleiro (Lippia gracilis); Vasconcelos et al. (2012) em branquinha (Gypsophila paniculata L.) e Tavares et al. (2012) em erva cidreira (Lippia alba).

Dessa forma, objetivou-se com o presente trabalho, verificar a influência de diferentes origens do material vegetal e de substratos na propagação vegetativa de romã (Punica granatum).

\section{MATERIAL E MÉTODOS}

O experimento foi conduzido no período de abril a julho de 2012, em casa de vegetação do Departamento de Ciências Vegetais da Universidade Federal Rural do Semiárido (UFERSA), em Mossoró no estado do Rio Grande do Norte, município localizado em área circunscrita às coordenadas geográficas $5^{\circ} 11^{\prime}$ de latitude sul, $37^{\circ} 20^{\prime}$ de longitude W. Gr., com $18 \mathrm{~m}$ de altitude, temperatura média anual em torno de $27,5^{\circ} \mathrm{C}$, umidade relativa de $68,9 \%$, nebulosidade média anual de 4,4 décimos e precipitação média anual de $673,9 \mathrm{~mm}$, com clima quente e seco, localizada na região semiárida do nordeste brasileiro (CARMO FILHO et al., 1991).

O delineamento estatístico utilizado foi inteiramente casualizado (DIC), em esquema fatorial $2 \times 3$, sendo duas origens do material vegetal coletado em Barreiras (Ceará) e em Mossoró (Rio Grande do Norte) e três substratos (Tropstrato ${ }^{\circledR}$, Fibra de coco e Solo), constituindo, assim, 6 tratamentos em quatro repetições. Cada repetição foi constituída por 5 estacas obtidas em plantas matrizes com cinco anos.

Na Tabela 1, encontram-se a descrição e composição química dos substratos estudados.

Tabela 1. Caracterização química dos substratos avaliados para propagação vegetativa de romã (Punica granatum), quanto a Condutividade Elétrica $(\mathrm{CE}), \mathrm{pH}$, teor de matéria orgânica $(\mathrm{MO})$, nitrogênio $(\mathrm{N})$, fósforo $(\mathrm{P})$, potássio $(\mathrm{K}+)$, sódio $(\mathrm{Na}+)$, cálcio $(\mathrm{Ca}+)$, magnésio $(\mathrm{Mg} 2+)$ e Alumínio $(\mathrm{Al3}+)$. Mossoró, Rio Grande do Norte

\begin{tabular}{|c|c|c|c|c|c|c|c|c|c|c|}
\hline \multirow{2}{*}{ Substratos } & \multirow{2}{*}{ C.E. } & & $\mathrm{MO}$ & $\mathrm{N}$ & $\mathrm{P}$ & $\mathrm{K}^{+}$ & $\mathrm{Na}^{+}$ & $\mathrm{Ca}^{2+}$ & $\mathrm{Mg}^{2+}$ & $\mathrm{Al}^{3+}$ \\
\hline & & $\left(\mathrm{H}_{2} \mathrm{O}\right)$ & $\left(\mathrm{g} \mathrm{kg}^{-1}\right)$ & $\left(\mathrm{mg} \mathrm{dm}^{-3}\right)$ & \multicolumn{6}{|c|}{$\left(\mathrm{cmol}_{\mathrm{c}} \mathrm{dm}^{-3}\right)$} \\
\hline Tropstrato $^{\circledR}$ & 1,92 & 6,1 & 12,92 & 1,12 & 10,0 & 176,0 & 19,5 & 11,0 & 2,5 & 14,04 \\
\hline Fibra de coco & 7,28 & 7,4 & 14,45 & 0,84 & 25,1 & 300,9 & 12,7 & 7,8 & 2,3 & 10,92 \\
\hline Solo & 0,7 & 6,9 & 0,31 & 0,33 & 35,0 & 56,2 & 0,11 & 4,1 & 2,0 & 0,05 \\
\hline
\end{tabular}

A coleta dos ramos foi realizada com auxílio de tesoura de poda no período da tarde, sendo introduzidos em recipientes contendo água, evitando assim, murcha dos mesmos e em seguida conduzidos à casa de vegetação, onde foram confeccionadas estacas semilenhosas, sem folhas, de $15 \mathrm{~cm}$.

As estacas foram colocadas em bandejas de poliestireno expandido de 50 células preenchidas com os substratos preestabelecidos. As irrigações foram feitas com regador no inicio da manhã e final da tarde, e cada estaca foi protegida com sacola de polietileno transparente até a emissão das brotações.

Aos 45 dias após a instalação do experimento foram avaliadas as variáveis: número de brotos por estaca, comprimento do maior broto, número de folhas por estacas, comprimento da maior raiz, porcentagem de estacas sobreviventes e enraizadas, número de raízes por estaca, massa seca da brotação e massa seca do sistema radicular, os materiais foram coletados, separadamente, e colocado para secar em estufa de circulação de ar forçado $\left(65^{\circ} \mathrm{C}\right)$ até obter massa constante, ocasião que foi realizada a pesagem em balança analítica com precisão de $0,001 \mathrm{~g}$.

Os dados obtidos foram submetidos à análise de variância pelo teste $\mathrm{F}$ e as médias comparadas pelo teste de Tukey, a 5\% de probabilidade com auxilio do programa computacional Sistema para Análise de Variância - SISVAR (FERREIRA, 2008). 


\section{RESULTADOS E DISCUSSÃO}

Constatou-se diferença significativa ao nível de $1 \%$ de probabilidade para as variáveis: comprimento da maior raiz (CR), comprimento do maior broto $(\mathrm{CB})$, número de folhas por estacas (NF), número de brotos por estaca (NB), número de raízes por estaca (NR), massa seca da brotação (MSB), massa seca do sistema radicular (MSR) e porcentagem de estacas enraizadas $(\% \mathrm{E})$ entre os materiais vegetais $\mathrm{e}$ substratos (Tabela 2). Verificou-se interação entre esses fatores, para todas as variáveis, exceto $\mathrm{MSB}, \mathrm{MSR}, \% \mathrm{~S}$ e $\% \mathrm{E}$. Para porcentagem de estacas sobreviventes $(\% \mathrm{~S})$ não foi verificada diferença entre os materias e substratos, com média de $74,1 \%$, esse valor é próximo do encontrado por Batista et al. (2011) em trabalho realizado com a mesma espécie, no qual o melhor resultado foi alcançado no substrato plantimax ${ }^{\circledR}$ $(70 \%)$.

Tabela 2. Resumo da análise de variância para comprimento da maior raiz (CR), comprimento do maior broto (CB), número de folhas por estaca (NF), número de brotos por estaca (NB), número de raízes por estaca (NR), massa seca da brotação (MSB), massa seca do sistema radicular (MSR), porcentagem de estacas sobreviventes (\%S) e enraizadas (\%E) de estacas de romã (Punica granatum), obtidas de diferentes origens (Barreiras e Mossoró) e submetido a diferentes substratos (Tropstrato ${ }^{\circledR}$, Fibra de coco e Solo). Mossoró, Rio Grande do Norte

\begin{tabular}{|c|c|c|c|c|c|c|c|c|c|}
\hline \multirow{2}{*}{ Fonte de variação } & \multicolumn{9}{|c|}{ Valores de F } \\
\hline & $\mathrm{CR}$ & $\mathrm{CB}$ & NF & NB & NR & MSB & MSR & $\% \mathrm{~S}$ & $\% \mathrm{E}$ \\
\hline Material vegetal (MV) & $116,9^{* * *}$ & $172,1^{* * *}$ & $123,8^{* * *}$ & $28,7^{* * *}$ & $256,8^{* * *}$ & $68,8^{* * *}$ & $10,7^{* *}$ & $0,1^{\mathrm{ns}}$ & $22,9^{* * *}$ \\
\hline Substratos $(\mathrm{S})$ & $58,7^{* *}$ & $91,9^{* *}$ & $69,36^{* *}$ & $10,9^{* * *}$ & $89,2^{* *}$ & $11,8^{* * *}$ & $29,9^{* *}$ & $1,4^{\mathrm{ns}}$ & $20,9^{* *}$ \\
\hline $\mathrm{MV} \times \mathrm{S}$ & $18,6^{* *}$ & $7,4^{* * *}$ & $22,0^{* *}$ & $23,4^{* * *}$ & $49,7^{* *}$ & $2,9^{\mathrm{ns}}$ & $2,6^{\mathrm{ns}}$ & $1,4^{\mathrm{ns}}$ & $2,4^{\mathrm{ns}}$ \\
\hline DMS & 0,6 & 0,8 & 2,9 & 0,3 & 0,8 & 0,1 & 0,01 & 10,5 & 8,5 \\
\hline $\mathrm{CV}(\%)$ & 25,4 & 13,9 & 21,6 & 12,3 & 22,3 & 28,2 & 35,2 & 16,5 & 15,5 \\
\hline Média Geral & 2,9 & 6,5 & 15,5 & 3,1 & 3,9 & 0,2 & 0,02 & 74,1 & 64,03 \\
\hline
\end{tabular}

Significativo a $1 \%$ de probabilidade; ${ }^{\text {ns }}$ Não significativo.

Observa-se na Tabela 3, que o material de Barreiras apresentou maior comprimento de raiz e brotações para todos os substratos estudados. O comprimento de raiz, no substrato Tropstrato ${ }^{\circledR}$ apresentou maior comprimento para os materiais 1 e 2 , correspondendo a 6,8 e $1,25 \mathrm{~cm}$, embora para o material 2 esse substrato não tem diferido dos demais substratos. Os substratos Tropstrato $^{\circledR}$ e fibra de coco promoveram as maiores brotações, independente do material. Batista et al. (2011) trabalhando com a mesma espécie observou maior comprimento médio das brotação no substrato fibra de coco. Souza et al. (2006) observaram que estacas de Acalypha wilkesiana tiveram maior comprimento de raiz em substrato fibra de coco, mas não verificaram efeito sobre o comprimento da brotação.

Tabela 3. Médias do comprimento da maior raiz (CR), comprimento do maior broto $(\mathrm{CB}, \mathrm{cm})$ e número de folhas por estacas (NF) de estacas de romã (Punica granatum), obtidas de diferentes origens (Barreiras e Mossoró) e submetido a diferentes substratos (Tropstrato ${ }^{\circledR}$, Fibra de coco e Solo). Mossoró, Rio Grande do Norte.

\begin{tabular}{|c|c|c|c|c|c|c|}
\hline \multirow{3}{*}{ Substrato/Material vegetal } & \multicolumn{6}{|c|}{ Médias } \\
\hline & \multicolumn{2}{|c|}{$\mathrm{CR}$} & \multicolumn{2}{|c|}{$\mathrm{CB}$} & \multicolumn{2}{|c|}{$\mathrm{NF}$} \\
\hline & Barreiras & Mossoro & Barreiras & Mossoro & Barreiras & Mossoro \\
\hline Tropstrato $^{\circledR}$ & $6,81 \mathrm{Aa}$ & $1,25 \mathrm{Bab}$ & $10,94 \mathrm{Aa}$ & $4,83 \mathrm{Ba}$ & $24,44 \mathrm{Ab}$ & $4,90 \mathrm{Bb}$ \\
\hline Fibra de coco & $5,4 \mathrm{Ab}$ & $2,50 \mathrm{Ba}$ & $11,46 \mathrm{Aa}$ & $5,88 \mathrm{Ba}$ & $37,64 \mathrm{Aa}$ & $14,00 \mathrm{Ba}$ \\
\hline Solo & $1,39 \mathrm{Ac}$ & $0,26 \mathrm{Bb}$ & $4,43 \mathrm{Ab}$ & $1,57 \mathrm{Bb}$ & $7,40 \mathrm{Ac}$ & $4,78 \mathrm{Ab}$ \\
\hline
\end{tabular}

"Médias seguidas pela mesma letra minúscula na coluna e maiúscula na linha não diferem estatisticamente entre si pelo teste de Tukey a 5\% de probabilidade.

A diferença encontrada entre os materiais vegetais podem estar relacionados a condição nutricional da plantamatriz que pode afetar fortemente o enraizamento. No que se refere ao teor de carboidratos, tem-se observado que reservas mais abundantes correlacionam-se com maiores percentagens de enraizamento e sobrevivência de estacas. Além disso, o desenvolvimento inicial das brotações e raízes ocorrem devido as substâncias endógenas localizadas internamente na estaca (FACHINELLO et al., 2005).

O maior número de folhas foi encontrado quando foram utilizadas estacas de Barreiras, nos substratos Tropstrato ${ }^{\circledR}$ $(24,4)$ e fibra de coco $(37)$, sendo o ultimo superior quando utilizado o material de Mossoró $(14,0)$. Esses valores são próximos dos obtidos por Batista et al. (2011) que obteve de 29,5 a 37,25 folhas/estaca, embora não tenha ocorrido diferença significativa entre os diferentes substratos (plantimax $^{\circledR}$, areia, arisco, fibra de coco e solo). Quando utilizado solo não houve diferença entre os materiais e foram verificados os menores números de folhas, 7,4 e 4,78, para os materiais de Barreiras e Mossoró, respectivamente.

O número de brotações e de raízes apresentaram respostas semelhantes, com o material de Barreiras apresentando melhores resultados em todos os substratos. No substrato fibra de coco houve maior número de brotações e raízes em todos os materiais, embora não tenha diferido no substrato Tropstrato ${ }^{\circledR}$ e material de Barreiras, para número de brotações e no material de Mossoró, para número de raízes (Tabela 4).

Batista et al. (2011), verificaram que o número de brotações de $P$. granatum foi maior no substrato Plantmax ${ }^{\circledR}$, que também é um substrato comercial. Em estudo de Lima e Ohashi, (2016) com Schizolobium parahyba var. amazonicum a vermiculita+fibra de coco e vermiculita+fibra de coco+areia apresentaram os melhores resultados e o ponto máximo de enraizamento ( 80 e $85 \%$, respectivamente) ocorreu aos 20 dias, sem incremento significativo a partir desse período. 
Tabela 4. Médias do número de brotos por estaca (NB), número de raízes por estaca (NR) de estacas de romã (Punica granatum), obtidas de diferentes origens (Barreiras e Mossoró) e submetidas a diferentes substratos (Tropstrato ${ }^{\circledR}$, Fibra de coco e Solo). Mossoró, Rio Grande do Norte.

\begin{tabular}{|c|c|c|c|c|}
\hline \multirow{3}{*}{ Substrato/Material vegetal } & \multicolumn{4}{|c|}{ Médias } \\
\hline & \multicolumn{2}{|c|}{ NB } & \multicolumn{2}{|c|}{ NR } \\
\hline & Barreiras & Mossoró & Barreiras & Mossoró \\
\hline Tropstrato $^{\circledR}$ & $4,12 \mathrm{Aa}$ & $1,83 \mathrm{Bc}$ & $6,64 \mathrm{Ab}$ & $1,66 \mathrm{Ba}$ \\
\hline Fibra de coco & $3,52 \mathrm{Aa}$ & $3,51 \mathrm{Aa}$ & $11,91 \mathrm{Aa}$ & $1,51 \mathrm{Ba}$ \\
\hline Solo & $2,73 \mathrm{Ab}$ & $2,58 \mathrm{Ab}$ & $1,77 \mathrm{Ac}$ & $0,5 \mathrm{Bb}$ \\
\hline
\end{tabular}

"Médias seguidas pela mesma letra minúscula na coluna e maiúscula na linha não diferem estatisticamente entre si pelo teste de Tukey a $5 \%$ de probabilidade.

A matéria seca das brotações, raízes e porcentagem de enraizamento, apresentaram respostas semelhantes entre os materiais de diferentes origens (Tabela 5). Para essas variáveis o substratos Tropstrato ${ }^{\circledR}\left(0,280 ; 0,0298 \mathrm{~g} \mathrm{estaca}^{-1} \mathrm{e}\right.$ $77,08 \%)$ e fibra de coco $\left(0,270 ; 0,0247 \mathrm{~g} \mathrm{estaca}^{-1}\right.$ e $\left.68,95 \%\right)$ apresentaram os melhores resultados. $\mathrm{O}$ solo apresentou os menores valores para essas variáveis, concordando com Batista et al., (2011) que verificaram que o solo é o pior substrato para estacas de romã.

Tabela 5. Médias de massa seca da brotação (MSB, g estaca ${ }^{-1}$ ), massa seca do sistema radicular (MSR, g estaca ${ }^{-1}$ ) e porcentagem de estacas enraizadas $(\% \mathrm{E})$ de estacas de romã obtidas de diferentes origens (Barreiras e Mossoró) e submetido a diferentes substratos (Tropstrato ${ }^{\circledR}$, Fibra de coco e Solo). Rio Grande do Norte.

\begin{tabular}{lccc}
\multirow{2}{*}{ Substratos } & \multicolumn{3}{c}{ Médias } \\
\cline { 2 - 4 } & MSB & MSR & $\% \mathrm{E}$ \\
\hline Tropstrato $^{\circledR}$ & $0,2805 \mathrm{a}$ & $0,0298 \mathrm{a}$ & $77,08 \mathrm{a}$ \\
Fibra de coco & $0,2708 \mathrm{a}$ & $0,0247 \mathrm{a}$ & $68,95 \mathrm{a}$ \\
Solo & $0,1417 \mathrm{~b}$ & $0,0045 \mathrm{~b}$ & $46,04 \mathrm{~b}$ \\
\hline
\end{tabular}

"Médias seguidas pela mesma letra minúscula na coluna não diferem estatisticamente entre si pelo teste de Tukey a 5\% de probabilidade.

Esses resultados são semelhantes ao encontrado por Souza et al. (2006) que observaram que estacas de Acalypha wilkesiana tiveram maiores taxas de enraizamento em substrato fibra de coco e são diferentes dos encontrados por Carvalho et al. (2007) que trabalhando com os substratos solo; solo + vermiculita $(1: 1) ;$ solo + vermiculita + vermicomposto $(1: 1: 1)$ na propagação vegetativa de carqueja, verificou que esses não influenciaram a porcentagem de enraizamento, com resultados superiores a $90 \%$, independente do substrato utilizado.

Costa et al. (2007) avaliando o comprimento da estaca e tipo de substrato (areia, plantimax ${ }^{\circledR}$ e palha de arroz) na propagação vegetativa de atroveran (Ocimum selloi Benth.) verificaram porcentagem de enraizamento entre 68 e $80 \%$, não havendo diferença entre os substratos. Nesse trabalho também não foi observada diferença para matéria seca das folhas, brotações e comprimento da raiz.

Oliveira et al. (2011) avaliando substratos sob dois genótipos de alecrim-de-tabuleiro (Lippia gracilis Schauer), observou que os materiais apresentaram porcentagem de enraizamento diferentes, independente do substrato.

Os efeitos do substrato, verificados no presente trabalho, tanto sobre o percentual de enraizamento quanto sobre a qualidade das raízes formadas, relacionam-se especialmente com a porosidade, a qual afeta o teor de água retida e seu equilíbrio com a aeração (FACHINELLO et al., 2005). Estas características foram proporcionadas pelos substratos Tropstrato $^{\circledR}$ e fibra de coco que apresentaram maior teor de matéria orgânica. Também é importante a nutrição proporcionada por estes substratos, com maior teor de nitrogênio, potássio e cálcio que o solo.

Pode ser interessante considerar o fator econômico na aquisição de substratos, e neste sentido os substratos comerciais são mais baratos que a fibra de coco. Assim, neste estudo, poderia ser indicado o substrato Tropstrato ${ }^{\circledR}$.

\section{CONCLUSÕES}

A propagação por estaquia de romã é influenciada pela origem do material vegetal e o melhor material é de Barreiras, CE.

Recomenda-se o substrato Tropstrato ${ }^{\circledR}$ para a produção de mudas de romã por estaquia.

\section{REFERÊNCIAS}

BATISTA, P. F.; MAIA, S. S. S.; COELHO, M. F. B. BENEDITO, C. P.; GUIMARÃES, I. P. Propagação vegetativa de romã em diferentes substratos. Revista Verde, v.6, n.4, p.96-100, 2011.

CARMO FILHO, F.; ESPÍNOLA SOBRINHO, J.; MAIA NETO, J. M. Dados climatológicos de Mossoró: um município semi-árido nordestino. Mossoró: ESAM, 1991. $121 \mathrm{p}$.

CARVALHO, R. I. N.; NOLASCO, M. A.; CARVALHO, T.; RIPKA, M.; GIUBLIN, L. M.; NEGRELLO, M.; SCHEFFER, M.C. Enraizamento de estacas de carqueja em função de diferentes substratos e posições do ramo em plantas masculinas e femininas. Scientia Agraria, v.8, n.3, p.269-274, 2007.

CHAGAS, J. H.; PINTO, J. E. B. P.; BERTOLUCCI, S. K. V.; NALON, F.H. Produção de mudas de hortelã-japonesa em função da idade e de diferentes tipos de estaca. Ciência Rural, v.38, n.8, p.2157-2163, 2008.

COELHO, M. F. B.; MAIA, S. S. S.; OLIVEIRA, A. K.; DIÓGENES, F.E.P.; SOARES, S.R.F. Propagação vegetativa de liamba, planta medicinal. Horticultura Brasileira, v.29, n.3, p.418-420, 2011.

CORRÊAA, P. M. Dicionário das plantas úteis do Brasil e das exóticas cultivadas. Rio de Janeiro: Imprensa Nacional, 1978. v.5, p.609-610.

COSTA, L. C. B.; PINTO, J. E. B. P; BERTOLUCCI, S. K. V. Comprimento da estaca e tipo de substrato na propagação 
vegetativa de atroveran. Ciência Rural, v.37, n.4, p.11571160, 2007.

FACHINELLO, J. C.; HOFFMANN, A.; NACHTIGAL, J. C. (Eds). Propagação de plantas frutíferas. Brasília: Embrapa Informações Tecnológicas, 2005. 221p.

FERREIRA, D. F. SISVAR: um programa para análises e ensino de estatística. Revista Symposium, v.6, n.2, p.36-41, 2008.

FERREIRA, M. G. R.; GONÇALVES, E. P. Estaquia e crescimento inicial de crajiru. Revista Brasileira de Biociências, v.5, n.1, p.363-365, 2007.

LIMA, C. C; OHASHI, S. T. Substrato no enraizamento de estacas provenientes de mudas de Schizolobium parahyba var. amazonicum. Enciclopédia Biosfera, Centro Científico Conhecer, Goiânia, v.13, n.23, p.1270-1282, 2016.

LIMA, D. M.; SILVA, C. L.; RITTER, M.; BIASI, L. A.; ZANETTE. F.; ZUFFELLATO-RIBAS, K.C. Substratos e auxinas no enraizamento de estacas caulinares de espinheirasanta. Scientia Agraria, v.9, n.1, p.85-89, 2008.

LORENZI, H.; MATOS, F. J. A. Plantas Medicinais: no Brasil: nativas e exóticas, 2 ed. Nova Odessa, SP: Instituto Plantarum, 2008.

LUSA, M. G; BIASI, L. A. Estaquia de Cuphea calophylla subsp. mesostemon (Koehne) Lourteig (Lythraceae). Revista brasileira de plantas medicinais, Botucatu, v.13, n.1, p.5257, 2011.

MAIA, S. S. S.; PINTO, J. E. B. P.; SILVA, F. N.; OLIVEIRA, C. Enraizamento de Hyptis suaveolens (L.) Poit. (Lamiaceae) em função da posição da estaca no ramo. Revista Brasileira de Ciências Agrárias, v.3, n.4, p.317-320, 2008.
MARIN, S. L. D.; GOMES, J. A.; SALGADO, J. S. Recomendação para a cultura do mamoeiro cv. Solo do Estado do Espírito Santo. 3. ed. Vitória: s. ed., 1987. 64p.

OLIVEIRA, A. C. L.; ARRIGONI-BLANK, M. F.; BLANK, A. F.; BIANCHINI, F. G. Produção de mudas de dois genótipos de alecrim-de-tabuleiro (Lippia gracilis Schauer) em função de fertilizante mineral, calcário, substratos e recipientes. Revista Brasileira de Plantas Medicinais, v.13, n.1, p.35-42, 2011.

SANTOS, F. M.; PINTO, J. E. B. P.; ALVARENGA, A. A.; OLIVEIRA, J. A.; OLIVEIRA, A. A.; OLIVEIRA, L. P. Produção de mudas de Aloysia gratissima (Gillies \& Hook.) Tronc. por meio da propagação sexuada e assexuada. Revista brasileira de plantas medicinais, v.11, n.2, p.130-136, 2009.

SILVA, A. C.; SILVEIRA, S. S. M.; COELHO, M. F. B.; PAIVA, E. P.; CUNHA, C. S. M. Comprimento de estacas na propagação vegetativa de bamburral (Hyptis suaveolens (L.) POIT.). Revista Caatinga, v.24, n.4, p.191-194, 2011.

SOUZA, C. S. S.; ALVES, M. C.; CASTILHO, R. M. M. Avaliação de substrato no enraizamento de estacas de acalifa (Acalypha wilkesiana). Revista Brasileira de Biociências, v.12, n.1-2, p.8-15, 2006.

TAVARES, I. B.; MOMENTÉ, V. G.; BARRETO, H. G.; CASTRO, H. G.; SANTOS, G. R.; NASCIMENTO, I. R. Tipos de estacas e diferentes substratos na propagação vegetativa da erva cidreira (quimiotipos I, II e III). Bioscience Journal, v.28, n.2, p.206-213, 2012.

VASCONCELOS, A. A.; INNECCO, R.; MATTOS, S. H. Influência de diferentes composições de substratos na propagação vegetativa de Gypsophila no litoral cearense. Revista Ciência Agronômica, v.43, n.4, p.706-712, 2012. 